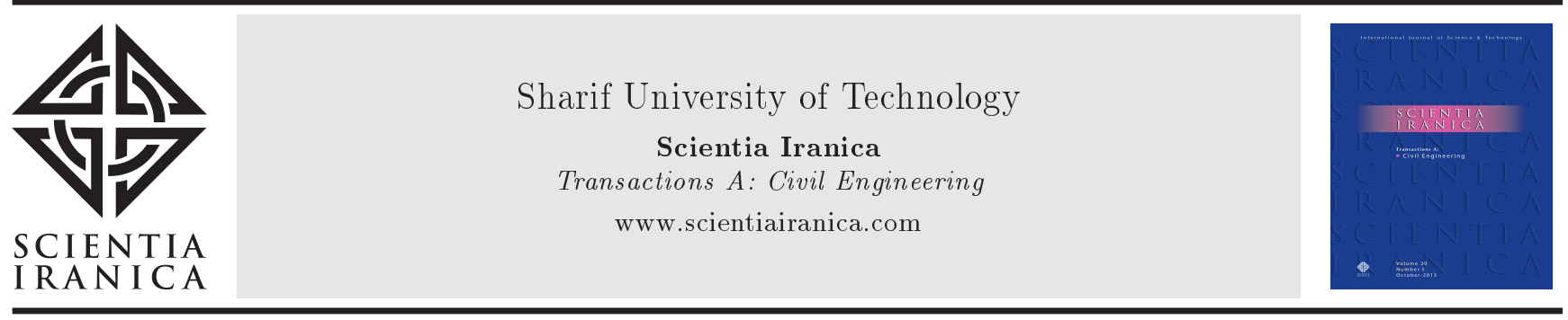

\title{
A different NSM FRP technique for strengthening of RC two-way slabs with low clear cover thickness
}

\author{
P. Behzard*, M.K. Sharbatdar and A. Kheyroddin \\ Faculty of Civil Engineering, Semnan University, Semnan, P.O. Box 35131-19111, Iran.
}

Received 22 February 2015; received in revised form 17 May 2015; accepted 27 June 2015

\section{KEYWORDS}

Manually made CFRP rods;

Manually made CFRP

strips;

GFRP rods;

NSM technique;

RC two-way slabs;

Finite element.

\begin{abstract}
An experimental program was carried out to investigate the effectiveness of a novel Near Surface Mounted (NSM) technique using innovative Manually Made CFRP Rods (MMRs) and Manually Made CFRP Strips (MMSs) for flexural strengthening of Reinforced Concrete (RC) two-way slabs with low clear cover thickness. Four full-scale RC slabs $(1500 \times 1500 \times 120 \mathrm{~mm})$ were tested under monotonic four-point bending. One slab was kept un-strengthened as the control specimen, one slab was strengthened using NSM GFRP rods, and the other two slabs were strengthened using NSM CFRP MMRs and NSM CFRP MMSs. The load-deflection responses, strain measurements, and failure modes of the tested slabs were studied and discussed. The behavior of slabs strengthened with this technique was compared to the behavior of the slab strengthened with GFRP rods. The test results confirmed the feasibility and efficacy of this technique in improving the flexural behavior of RC two-way slabs. Strengthened slabs showed an increase in flexural capacity between $279 \%$ and $394 \%$ over the control specimen. A 3D nonlinear numerical model was developed using the Finite Element (FE) method to predict the flexural behavior of the tested slabs. A good agreement between experimental and numerical results was observed.

(C) 2016 Sharif University of Technology. All rights reserved.
\end{abstract}

\section{Introduction}

Fiber Reinforced Polymer (FRP) reinforcement has shown to be an effective material to increase the flexural and shear capacity of Reinforced Concrete (RC) structures. Advantages of FRP material for strengthening over traditional methods are: high strength to weight ratio, high fatigue strength, no corrosion, and high chemical resistance $[1,2]$.

The Near Surface Mounted (NSM) method is an emerging strengthening technique for RC structures, which is based on bonding the FRP reinforcements into pre-cut grooves in the concrete cover. Such grooves

*. Corresponding author. Tel.: +98 2144260750 ;

Fax: +982144480149

E-mail addresses: pejmanb@gmail.com (P. Behzard);

msharbatdar@semnan.ac.ir (M.K. Sharbatdar);

kheyroddin@semnan.ac.ir (A. Kheyroddin) might be in the tensile faces of the $\mathrm{RC}$ members for flexure strengthening or sides of the beams for shear strengthening as well as along the height of columns [35]. In recent years, research on the NSM FRP reinforcement strengthening technique has attracted considerable attention and the results have shown the effectiveness of this technique in improving the flexural and shear behavior of RC structural members. De Lorenzis and Teng [6] presented a critical review of existing research on strengthening of structural members using the NSM FRP reinforcement technique.

The efficiency of the NSM technique for the flexural and shear strengthening of RC members has already been assessed $[7,8]$. However, most of the studies have focused on the strengthening of RC beams [9-12] or slab strips [13-17]. There are little experimental or analytical studies on the behavior of RC two-way slabs flexurally strengthened with NSM FRP reinforcements.

The flexural capacity of RC two-way slabs can 
Table 1. Material properties.

\begin{tabular}{|c|c|c|c|c|c|c|}
\hline Material & $\begin{array}{c}\text { Elastic } \\
\text { modulus } \\
(\mathrm{GPa})\end{array}$ & $\begin{array}{c}\text { Compressive } \\
\text { strength } \\
(\mathrm{MPa}) \\
\end{array}$ & $\begin{array}{c}\text { Yield } \\
\text { stress } \\
(\mathrm{MPa})\end{array}$ & $\begin{array}{c}\text { Yield } \\
\text { strain } \\
\text { ( } \mu \text { strain) }\end{array}$ & $\begin{array}{c}\text { Ultimate } \\
\text { tensile } \\
\text { stress (MPa) }\end{array}$ & $\begin{array}{c}\text { Ultimate } \\
\text { tensile } \\
\text { strain ( } \mu \text { strain })\end{array}$ \\
\hline Concrete $^{a}$ & 24.91 & 24.82 & - & - & - & - \\
\hline Steel $^{a}$ & 200 & - & 351.15 & 2,160 & 520.85 & 159,332 \\
\hline GFRP $\operatorname{rod}^{\mathrm{b}}$ & 60 & - & - & - & 1,000 & 15,000 \\
\hline CFRP fabric ${ }^{b}$ & 230 & - & - & - & 4,900 & 15,000 \\
\hline Sikadur $30^{\mathrm{b}}$ & 4.5 & - & - & - & 25 & 10,000 \\
\hline Sikadur $300^{\mathrm{b}}$ & 3.5 & - & - & - & 45 & 15,000 \\
\hline
\end{tabular}

be increased by bonding the FRP rods or strips into grooves cut perpendicularly on the tension face. For two-way slabs, the NSM strengthening technique using the FRP reinforcement must be performed along two perpendicular directions. Foret and Limam [18] investigated experimentally the flexural behavior of RC two-way slabs with two strengthening techniques: NSM CFRP rods and Externally Bonded (EB) CFRP strips. The experimental study consisted of three full-scale strengthened slabs in addition to one un-strengthened slab as the control specimen. It was concluded that the NSM technique improved the bearing capacity of RC two-way slabs. A more ductile behavior was also observed comparing to the EB technique. It was shown that the specimen strengthened using EB CFRP strips experienced the premature debonding failure of the strips and carried approximately half the load carried by the specimen strengthened using NSM CFRP rods. However, it should be mentioned that this technique can only be applied for slabs with sufficient clear cover thickness, because the grooves in one direction must be cut deeper than those in another direction. Therefore, this NSM strengthening technique is often limited, because the sufficient clear cover thickness is not available in most existing RC slabs. To overcome this drawback, an innovative NSM technique for strengthening of RC two-way slabs through Manually Made CFRP Rods (MMRs) and Manually Made CFRP Strips (MMSs), manufactured manually by CFRP fabric, is proposed in this study.

\section{Research significance}

The main objective of this study is to investigate the feasibility and efficacy of an NSM strengthening technique using innovative CFRP MMRs and CFRP MMSs to increase the positive bending flexural capacity of existing RC two-way slabs with low clear cover thickness. To the authors' knowledge, the technique introduced in this study is the first investigation in the technical literature into the use of manually made FRP reinforcements for strengthening of the $\mathrm{RC}$ two-way slabs. An experimental program of four-point bending tests is carried out on the RC two-way slabs with a limited amount of internal steel reinforcements. To assess the effectiveness of this technique, a comparison is carried out between the behavior of slabs strengthened according to this technique and the behavior of the slab strengthened with conventional GFRP rods. A 3D nonlinear Finite Element (FE) simulation is also developed using the FE code ANSYS [19] to predict the behavior of flexurally strengthened slabs. The FE numerical predicted load-central deflection responses and failure modes are compared with those of the measured experimental results.

\section{Experimental program}

\subsection{Material properties}

Table 1 summarizes the material properties of the concrete, steel bars, FRP reinforcements, and epoxy used for test specimens. The average 28-day compressive strength and ultimate compressive strain of concrete from compressive cylinder tests were $24.82 \mathrm{MPa}$ and 2,985 microstrain, respectively. The steel reinforcements were $10 \mathrm{~mm}$ diameter deformed steel bars with the mean yield strength of 351.15 MPa obtained from uniaxial tension tests. The FRP reinforcements used in the strengthening application consisted of GFRP rods and flexible CFRP sheets. The rods used in this investigation were GFRP pultruded rods made of continuous E-glass fibers and vinyl-ester resin. The nominal diameter of the rods was $12 \mathrm{~mm}$, and their surface was spirally ribbed. The sheets used in the strengthening application consisted of a custom stitched unidirectional carbon fabric. The thickness and width of the fabric were $0.13 \mathrm{~mm}$ and $500 \mathrm{~mm}$, respectively. The type and size of the FRP reinforcements were chosen based on commercial availability; however, there was a good agreement between the axial stiffness of the different FRP materials used for test specimens. For bonding the FRP reinforcements to the 
concrete, Sikadur 30 structural epoxy paste adhesive was used, which is a two-component epoxy matrix material. For manufacturing MMRs and MMSs, Sikadur 300 epoxy impregnation resin was used.

\subsection{Manufacturing CFRP MMRs and CFRP $M M S s$}

The proposed MMRs and MMSs were manufactured manually by CFRP fabric based on the lay-up technique. For manufacturing MMRs, four strips of CFRP fabric were cut by $1500 \mathrm{~mm}$ in length and $250 \mathrm{~mm}$ in width. The width of the strips was selected based on the design requirements and their length was equal to the dimension of the slab specimen. Twenty pieces of a $6 \mathrm{~mm}$ diameter wooden bar with a circular cross section were cut by $260 \mathrm{~mm}$ in length. One of the CFRP strips was impregnated with epoxy and then spread on a flat surface. In order to provide desirable workability for manufacturing MMRs and MMSs, a low viscosity epoxy impregnation resin, Sikadur 300, was used. Five wooden bars were aligned along the length of the CFRP strip as the end of each piece was about $50 \mathrm{~mm}$ away from the beginning of the next piece (Figure 1(a)). After that, the CFRP strip was wrapped uniformly around the wooden bars (Figure 1(b)). The prepared MMR had a wooden bar in the first $260 \mathrm{~mm}$ along its length, but there was no wooden bar in the next $50 \mathrm{~mm}$ after that. The free spaces between the subsequent wooden bars were repeated along the length of the prepared CFRP MMR with the same proportion. Consequently, four portions along the length of the prepared CFRP MMR were without wooden bars. Some pressure was applied on the prepared CFRP MMR by hand along the fiber direction to remove air bubbles entrapped between CFRP layers. After wrapping the CFRP strip and before drying the epoxy adhesive, those four portions without wooden bars along the length of the prepared CFRP MMR were compressed by hand, in order to compress and bond the CFRP layers with each other (Figure 1(c)). Four clips were attached to those four portions until the epoxy hardened. Four CFRP MMRs were prepared similarly. The final diameter of the prepared MMRs was $12 \mathrm{~mm}$, approximately. Figure 1(d)-(f) show the prepared CFRP MMR. Finally, the prepared MMRs were allowed to be cured for five days. The complementary details related to the mechanical properties of the MMRs through tension coupon test can be found in [20].

For manufacturing MMSs, four strips of CFRP fabric were cut by $1500 \mathrm{~mm}$ in length and $250 \mathrm{~mm}$ in width. One of the CFRP strips was impregnated with epoxy and then spread on a flat surface. After that, the CFRP strips were folded on each other by the width of the strip for three times and then bonded with each other (Figure 2(a)). Air bubbles entrapped between the CFRP layers were removed by hand. Four CFRP MMSs were prepared similarly. The final width and
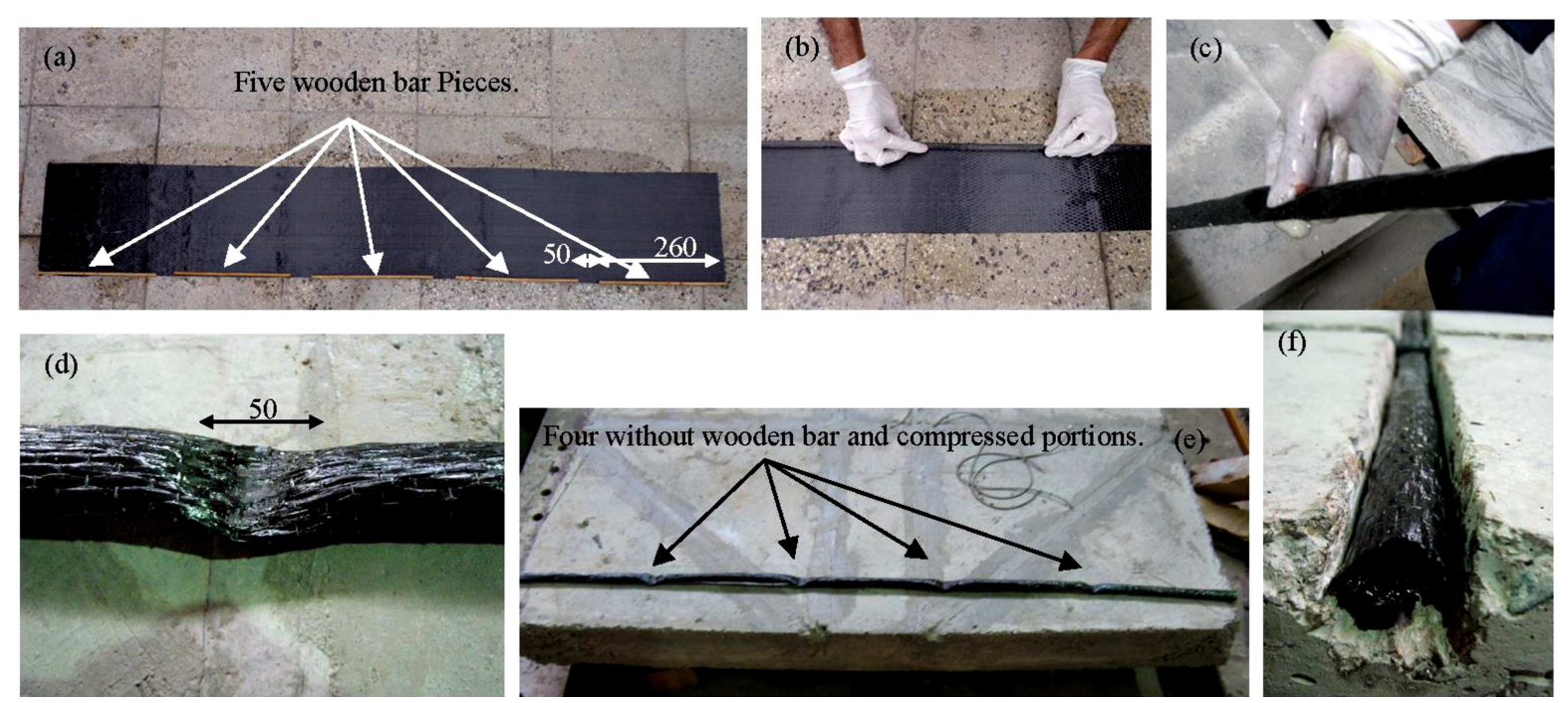

Figure 1. Manufacturing process of CFRP MMRs.
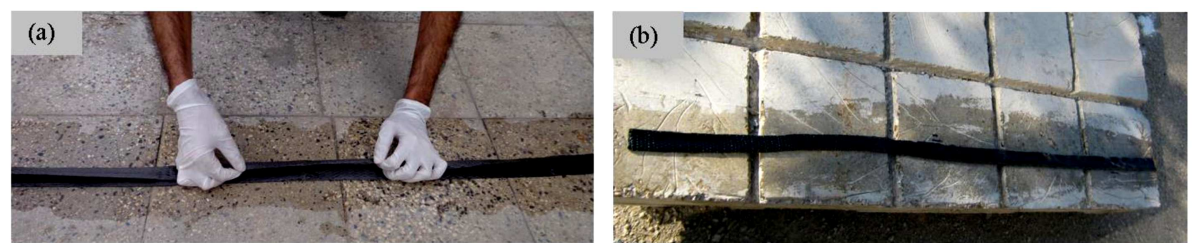

Figure 2. Manufacturing process of CFRP MMSs. 
thickness of the prepared MMSs were 30 and $3.5 \mathrm{~mm}$, respectively. Figure 2(b) shows the prepared CFRP MMS.

\subsection{Test specimens}

Four full-scale RC two-way slab specimens were constructed with the same geometrical configuration and steel reinforcement details. The dimensions of the slabs were $1,500 \mathrm{~mm}$ long $\times 1,500 \mathrm{~mm}$ wide $\times 120 \mathrm{~mm}$ thick. The sides of the slabs represent the contraflexure lines in an actual two-way slab system. The slabs were designed to obtain a pure flexural failure mode for the control specimen and possibly improve the flexural behavior of the strengthened specimens. The main flexural reinforcements (in one layer near the slab tension face) were 5-10 mm diameter deformed steel bars spaced at $300 \mathrm{~mm}$ along two perpendicular directions and arranged to give an average effective depth $(d)$ to the center of the two layers of $80 \mathrm{~mm}$. Thus, the clear cover thickness was about $30 \mathrm{~mm}$. The reinforcement area provided in the slabs corresponded to reinforcement ratio of about $0.22 \%$, which was close to the minimum reinforcement ratio for RC two-way slabs $(0.2 \%)$, as specified by ACI 318-99 [21]. The anchorage of these bars was provided by 180 degree hooks at both ends. Figure 3 shows the layout of a test specimen and steel reinforcement details.

\subsection{Strengthening method}

After curing, the specimens were rotated in 180 degrees around their in-plane axis and placed on an elevated platform for strengthening. Out of the four specimens, one was kept un-strengthened as the control specimen. Control specimen simulates an existing RC slab requiring strengthening. The other three specimens were strengthened using different configurations of NSM FRP reinforcements at the tension face of the slab. The amount and configuration of the FRP reinforcements were selected to provide a reasonable enhancement in the flexural capacity of the specimen. The specimens were named according to the different materials used for strengthening. The first and second phrases denoted the strengthening material in $x$ and $y$ directions, respectively. The GFRP rod, manually made CFRP rod, and manually made CFRP strip were denoted as R, MMR, and MMS, respectively.

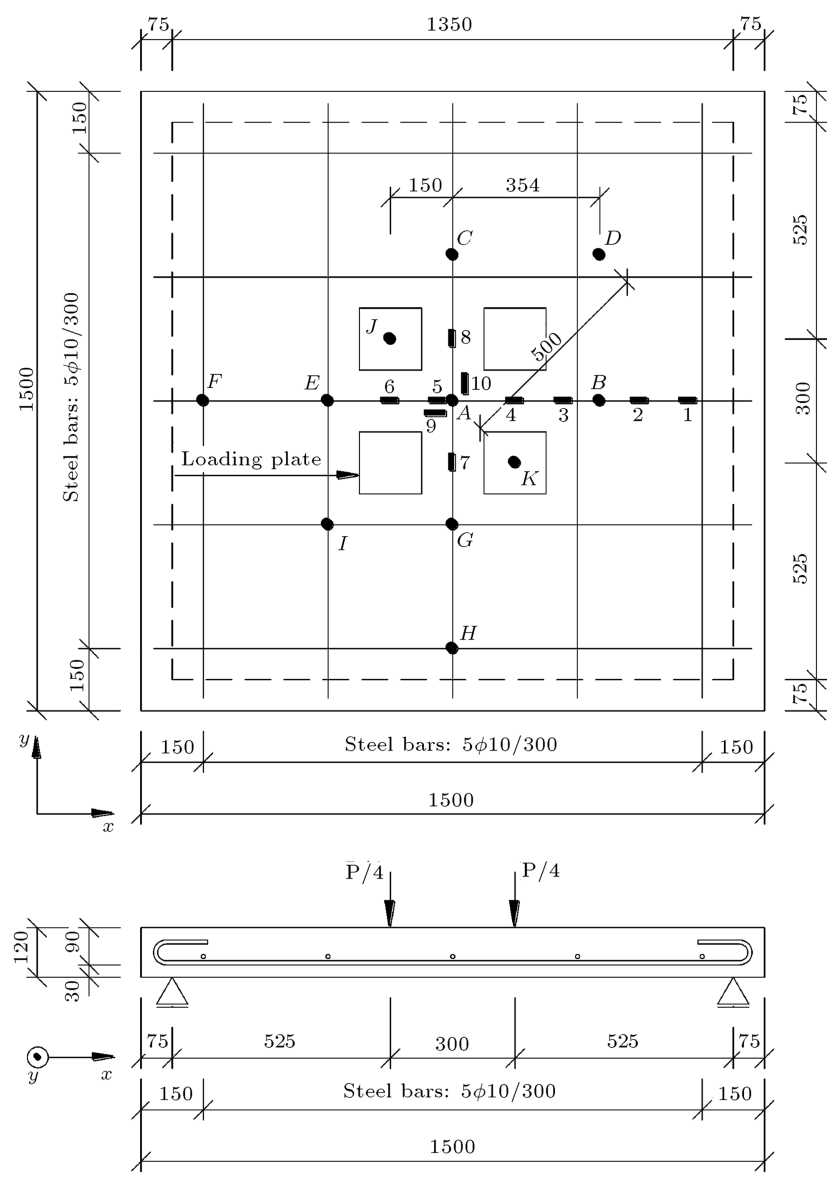

Figure 3. Test specimen layout and steel reinforcement details (all dimensions in $\mathrm{mm}$ ).

Therefore, the specimens were named as R-R, R-MMR, and R-MMS. The specimen designation, description of FRP reinforcements, and groove dimensions for specimens are given in Table 2.

The specimen R-R was strengthened using 4$12 \mathrm{~mm}$ diameter NSM GFRP rods in both $x$ and $y$ directions. The GFRP rods (1500 $\mathrm{mm}$ in length), spaced at $300 \mathrm{~mm}$, were bonded into grooves on the slab tension face. When the concrete slabs attained, approximately, 28 days of age, eight grooves were cut into the concrete cover along two perpendicular directions on the tension face of the slabs. The grooves were spaced at $300 \mathrm{~mm}$ centers. For specimen R-R, the grooves in $x$ direction were cut $10 \mathrm{~mm}$ deeper than

Table 2. Specimen designation, FRP layout description, and groove dimensions.

\begin{tabular}{ccccc}
\hline $\begin{array}{c}\text { Specimen } \\
\text { designation }\end{array}$ & $\begin{array}{c}\text { Reinforcement } \\
\text { material in } \\
\boldsymbol{x} \text { direction }\end{array}$ & $\begin{array}{c}\text { Reinforcement } \\
\text { material in } \\
\boldsymbol{y} \text { direction }\end{array}$ & $\begin{array}{c}\text { Groove size } \\
\text { in } \boldsymbol{x} \text { direction } \\
\boldsymbol{b} \times \boldsymbol{h}(\mathbf{m m})\end{array}$ & $\begin{array}{c}\text { Groove size in } \\
\boldsymbol{y} \text { direction }\end{array}$ \\
\hline Control & - & - & - & - \\
R-R & GFRP rod & GFRP rod & $20 \times 30$ & $20 \times 20$ \\
R-MMR & GFRP rod & CFRP MMR & $20 \times 23$ & $20 \times 20$ \\
R-MMS & GFRP rod & CFRP MMS & $20 \times 23$ & $30 \times 20$ \\
\hline
\end{tabular}



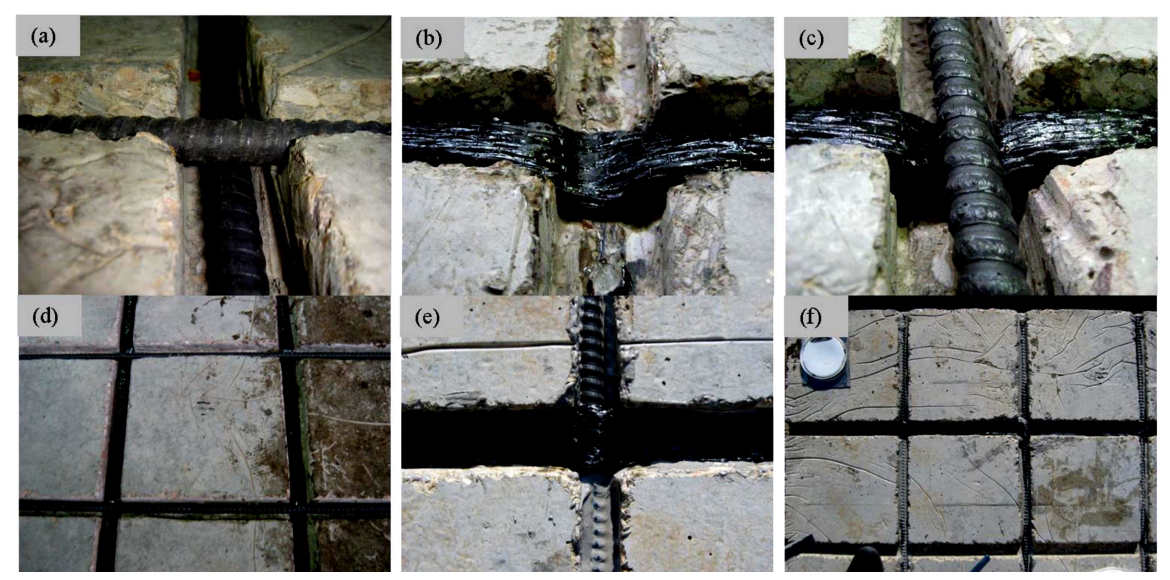

Figure 4. Strengthening process of slab specimens.

those in $y$ direction, as indicated in Table 2. A special concrete saw with a diamond blade was used to cut the grooves. The grooves were thoroughly cleaned of debris and dust using steel brushes and pressured air to ensure proper bonding between the epoxy adhesive and the concrete. Each groove was then half filled with the epoxy using a spatula, and the GFRP rods were subsequently inserted and lightly pressed. This forced the epoxy to penetrate around the rod and fill the space between the GFRP rod and the sides of the groove. At the grooves intersection, the GFRP rods, placed along two perpendicular directions, were passed on top of each other, as shown schematically in Figure 4(a). More epoxy was applied to fill the groove and the surface was leveled by removing the excess adhesive. The specimen was cured for one week at room temperature before testing.

The specimens R-MMR and R-MMS were similarly strengthened in $x$ direction using four NSM GFRP rods with the same arrangement as that of the specimen R-R, but they used, respectively, four CFRP MMRs and four CFRP MMSs as the strengthening reinforcements in $y$ direction. For specimens R-MMR and R-MMS, the grooves were cut in the same way as specimen $\mathrm{R}-\mathrm{R}$, except that the grooves in $x$ direction were cut only $3 \mathrm{~mm}$ deeper than those in $y$ direction, as indicated in Table 2. Therefore, the grooves in both directions had a same depth, approximately. For specimen R-MMR, four CFRP MMRs (1500 mm in long), spaced at $300 \mathrm{~mm}$, were bonded into grooves on the slab tension face in $y$ direction. At the grooves intersection, the GFRP rods were passed on top of the CFRP MMRs at those four compressed portions without wooden bar, as shown schematically in Figures 4(bd). As a result, both the GFRP rods and CFRP MMRs could be fitted into the limited depth of the groove. For specimen R-MMS, four CFRP MMSs (1500 mm in long), spaced at $300 \mathrm{~mm}$, were bonded horizontally into grooves on the slab tension face in y-direction. At the grooves intersection, the CFRP MMSs were passed

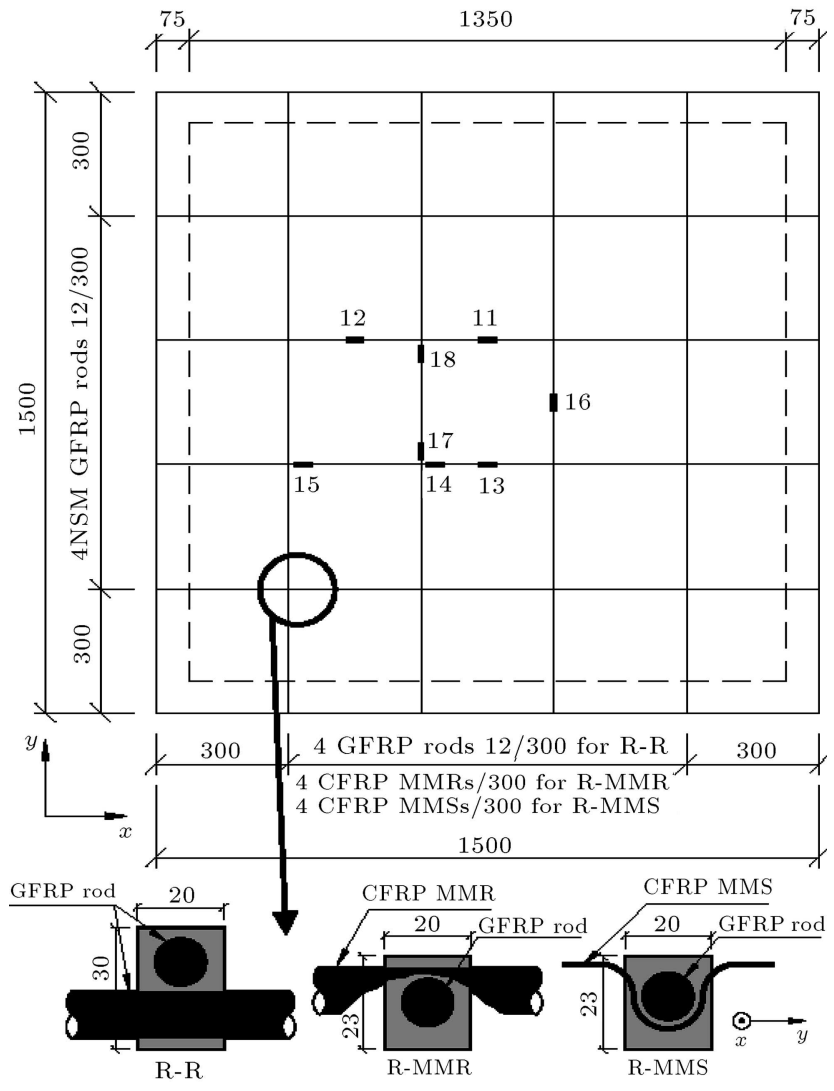

Figure 5. Schematic layout of the strengthened specimens and FRP reinforcement details at the grooves intersection.

on top of the GFRP rods, as shown schematically in Figure 4(e) and (f), in order to prevent separation of the GFRP rods from the groove sides. Therefore, both the GFRP rods and CFRP MMSs could be fitted into the limited depth of the groove, too. All the FRP reinforcements were extended to the exterior edges of the slab to allow utilization of a sufficient bond length of the FRP reinforcements. The specimens were cured for one week at room temperature before testing. Figure 5 shows a schematic layout of the three FRP 
strengthened specimens and FRP reinforcement details at the grooves intersection.

It should be mentioned that flexural strengthening of RC two-way slabs with low clear cover thickness, using NSM FRP rods in one direction and EB FRP strips or pre-cured FRP laminates in the other direction, can be an alternative choice for the strengthening technique proposed in this study, because of easier fabrication and installation process of EB FRP reinforcements than those of the MMRs and MMSs. But, in this study, based on the experimental results conducted by Foret and Limam [18] and those reported by other studies, it was concluded that the EB FRP strips or pre-cured FRP laminates experience the premature debonding failure at high load levels and the final flexural behavior of specimen is not achieved due to early debonding failure. Therefore, further investigations are not carried out to evaluate the effectiveness of this strengthening technique.

\subsection{Test setup and instrumentation}

The slabs were placed on a stiff supporting steel frame along their four sides. The stiff supporting frame rested on the strong concrete floor of the laboratory. Four steel rollers, $1350 \mathrm{~mm}$ apart on center, were placed between the four sides of the specimen and the stiff supporting frame. This simulates the simple supports over the four edges of the specimen, thus permitting the corners to uplift when load is applied. A stiff loading steel frame was used to test the specimens. All slabs were tested under monotonic load using a $500 \mathrm{kN}$ hydraulic jack in four-point bending up to failure. The loading points and supports were selected to give an effective span of $1350 \mathrm{~mm}$ and a shear span of $300 \mathrm{~mm}$ in both directions, as shown in Figure 3. A cruciform spreader steel beam was used to transfer the load to the slab through four loading points. Four square steel loading plates $(150 \times 150 \times 40 \mathrm{~mm})$ were placed between the cruciform spreader beam arms and slab top face to avoid uneven application of the load. The load was gradually increased by successive $10 \mathrm{kN}$ increment, which was progressively reduced to near failure. The self-weight of the slab was small and neglected in the calculation of the applied loads. The test was stopped when the specimen failed.

The applied load was measured using a $500 \mathrm{kN}$ load cell placed between the hydraulic jack and the stiff loading frame. The vertical deflection of the specimen was measured at eleven different locations using Linear Variable Displacement Transducers (LVDTs), denoted by points $\mathrm{A}$ to $\mathrm{K}$ in Figure 3 . The LVDTs were attached to a stiff instrumentation steel frame placed below the slab bottom face and fixed at the base. One of the LVDTs was placed underneath the slab center to measure the central deflection of the specimen. Six LVDTs were placed along the orthogonal central lines to measure the deflection at 300, 345, and $600 \mathrm{~mm}$ away from the slab center. The other four LVDTs were placed along the diagonal lines at 212, 424, and $500 \mathrm{~mm}$ away from the slab center. Eight strain gauges, denoted as 1 to 8 in Figure 3, were bonded at different locations on the steel bars in each specimen. Concrete strains were also measured on the slab compressive face along two perpendicular directions using two strain gauges, denoted as 9 and 10 in Figure 3. Based on the configuration of FRP reinforcements embedded in the slab tension face, eight gauges, denoted as 11 to 18 in Figure 5, were bonded to the FRP reinforcements at different locations. The locations of the strain gauges were selected in order to measure the maximum strains and to plot the strain distribution in the steel bars. Before bonding the gauges, the surface of the steel bars and GFRP rods were smoothed using an electrical disk sander and then cleaned with a solvent material. The readings from the load cell, LVDTs, and strain gauges were recorded by means of a data logger system. Figure 6 shows test setup and locations of the instruments.

\section{Test results and discussion}

\subsection{Load-deflection response}

Table 3 summarizes the test results including the ultimate load and deflection measurements for test specimens.

Figure 7 compares the load-central deflection responses of all four test specimens. Central deflec-

Table 3. Summary of test results.

\begin{tabular}{|c|c|c|c|c|c|c|c|c|c|c|}
\hline Specimen & $\begin{array}{c}P_{c r} \\
(\mathbf{k N})\end{array}$ & $\begin{array}{c}\boldsymbol{P}_{y} \\
(\mathbf{k N})\end{array}$ & $\begin{array}{c}P_{u} \\
(\mathrm{kN})\end{array}$ & $\begin{array}{c}\boldsymbol{P}_{p f} \\
(\mathbf{k N})\end{array}$ & $\begin{array}{c}\Delta_{c r} \\
(\mathbf{m m})\end{array}$ & $\begin{array}{c}\Delta_{y} \\
(\mathbf{m m})\end{array}$ & $\begin{array}{c}\Delta_{u} \\
(\mathbf{m m})\end{array}$ & $\begin{array}{c}\% \text { increase in } \\
P_{u} \text { with } \\
\text { respect to } \\
\text { control }\end{array}$ & $\begin{array}{c}\% \text { decrease in } \\
\Delta_{u} \text { with } \\
\text { respect to } \\
\text { control }\end{array}$ & $\begin{array}{c}\text { Displacement } \\
\text { ductility } \\
\left(\Delta_{u} / \Delta_{y}\right)\end{array}$ \\
\hline Control & 22.83 & 42.50 & 47.50 & - & 0.96 & 15.01 & 63.35 & - & - & 4.22 \\
\hline $\mathrm{R}-\mathrm{R}$ & 25.68 & 189.85 & 234.50 & 68.00 & 0.69 & 13.85 & 22.93 & 393.68 & 63.80 & 1.66 \\
\hline R-MMR & 24.22 & 143.17 & 213.17 & 103.00 & 0.71 & 11.83 & 21.06 & 348.78 & 66.76 & 1.78 \\
\hline R-MMS & 23.73 & 164.83 & 180.17 & 113.83 & 0.65 & 17.76 & 33.09 & 279.31 & 47.77 & 1.86 \\
\hline
\end{tabular}




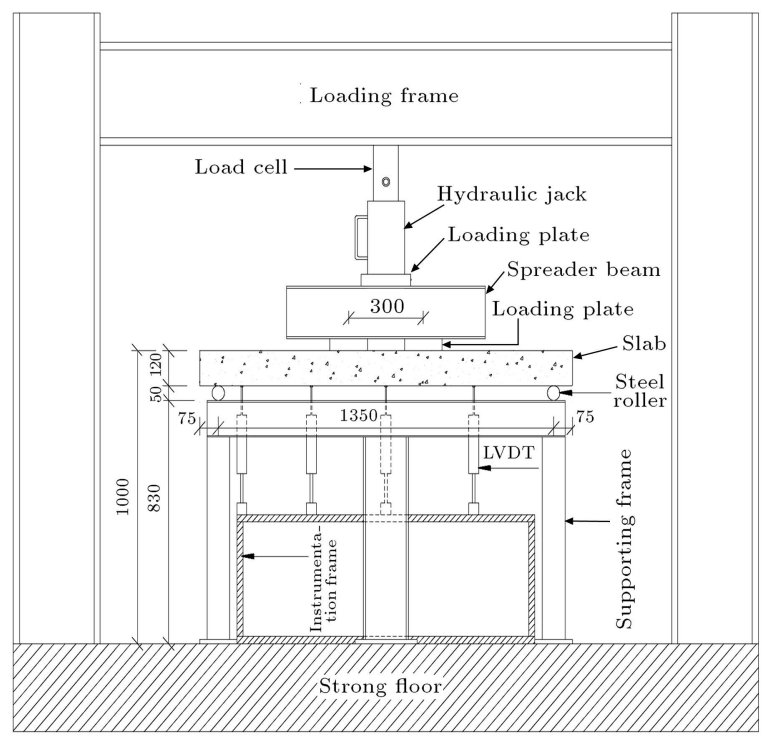

(a) Instrumentation

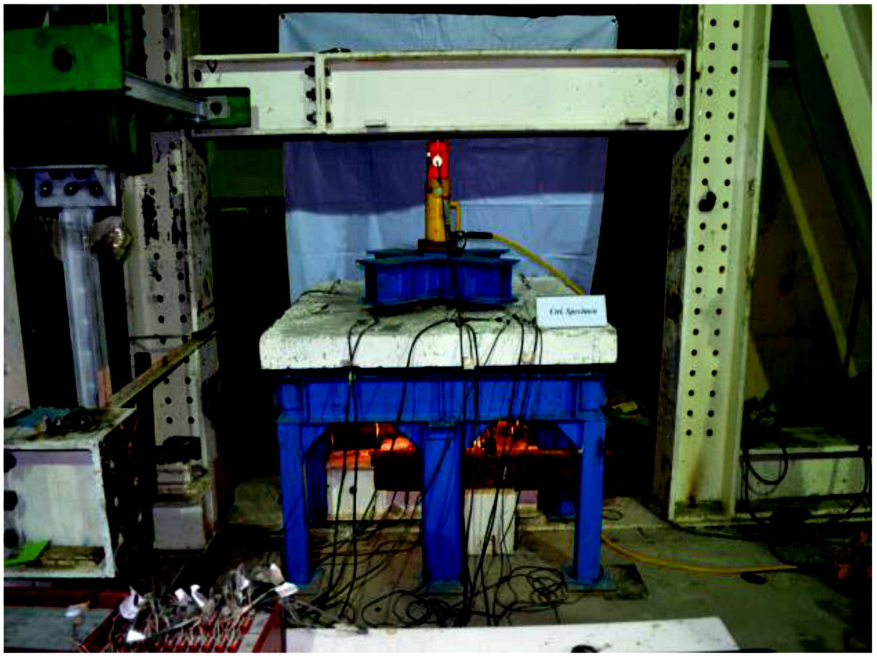

(b) Test setup

Figure 6. Test setup and locations of the instruments.

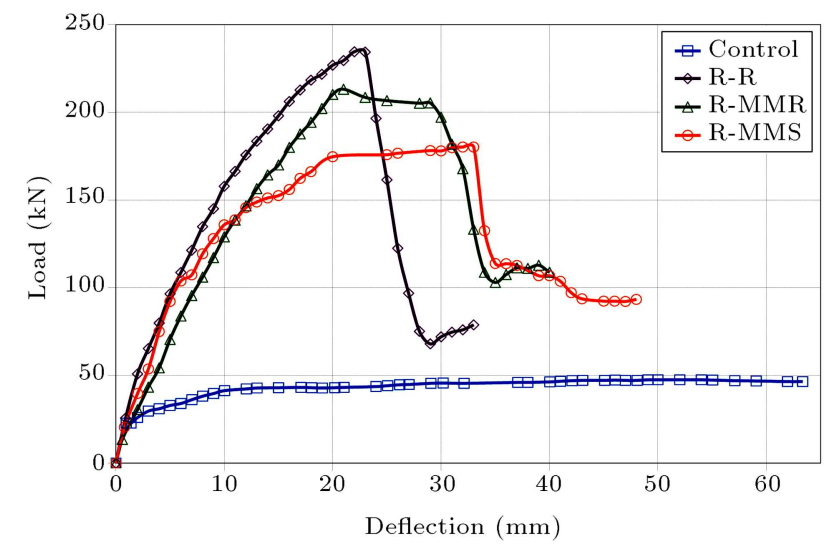

Figure 7. Comparison of load-deflection responses of specimens.

tions shown in these plots represent central deflections relative to supports. The load-deflection response can be divided into un-cracked and cracked stages. The cracked stage can also be divided into pre-yield and post-yield sub-stages. The pre-yield cracked stage is from the cracking load $\left(P_{c r}\right)$ to the yield load $\left(P_{y}\right)$. The post-yield cracked stage extends from the yield load $\left(P_{y}\right)$ to the ultimate load $\left(P_{u}\right)$. The first cracking load can be considered as the point where the loaddeflection response deviates from the initial elastic response. $P_{p f}$ is the post-failure load carrying capacity of the specimen.

A ductile failure was observed for the control specimen. The load-deflection response of the control specimen consisted of a stiff un-cracked stage followed by a yield plateau due to yield of the steel bars. Yielding spread gradually from the slab center to the edges as the applied load increased, which caused the formation of some yield lines. Finally, the specimen failed in pure flexural mode. The strengthened specimens exhibited combined flexural and local failure due to punch of the loading plates through the slab. Failure took place after significant yielding of flexural reinforcement. As the applied load increased further, the regions near the loading plates entered into a plastic state, and the loading plates punched through the slab thickness. Finally, failure occurred in a brittle manner and the load carrying capacity dropped in all strengthened specimens. Punching the loading plates through the slab thickness at high load levels (between 4.94 and $3.79 \%$ times the ultimate load measured for the control specimen) is natural in the four-point loading method in lowthickness two way slabs and sometimes it is unavoidable.

It can be seen by comparing the load-deflection responses of the specimens shown in Figure 7 and the ultimate load results presented in Table 3 that applying FRP reinforcements increases the cracking strength and flexural stiffness of the specimens, and results in considerable improvement in the flexural capacity. The corresponding increases depend on the area of the FRPs relative to the area of the conventional steel bars and the failure mode of the specimens. In addition, the load level at which the steel bars yielded $\left(P_{y}\right)$ depends on the FRP reinforcements area and configuration. The formation of yield lines is also influenced by the FRP reinforcements which tend to restrain the crack propagation.

\subsection{Ultimate load and deflection}

The control specimen experienced the lowest ultimate load $(47.50 \mathrm{kN})$. All the strengthened specimens had higher loading capacity than that of the 
control specimen. The specimens R-MMR and RMMS had increase in the ultimate load almost by 279 and $349 \%$, respectively, over the control specimen. Specimen R-R, strengthened by GFRP rods, showed higher increase in the ultimate load, which was $394 \%$ over the control specimen. The control specimen had the highest deflection value $(63.35 \mathrm{~mm})$ at the corresponding ultimate load. Deflection values at the ultimate loads of the strengthened specimens were between 33 and $52 \%$ of the deflection value of the control specimen due to the stiffening effect of FRP reinforcements. Displacement ductilities, defined as the ratio of deflection at the ultimate load divided by the deflection at the first yield, were 4.22, 1.66, 1.78, and 1.86 for specimens Control, R-R, R-MMR, and R-MMS, respectively. Specimens R-MMR and R-MMS showed high ductility compared to specimen R-R, but less ductility than the control specimen. It was shown that the increase in flexural capacity was accompanied by a reduction in the ductility of failure.

\subsection{Deflection profile}

Deflection of the specimens at 0,300,345, and $600 \mathrm{~mm}$ away from the slab center along the orthogonal axis and at $0,212,425$, and $500 \mathrm{~mm}$ along the diagonal axis was measured continuously with increasing the applied load. At any load level, the highest deflection value was at the slab center, and deflections decreased with increase in the distance from the slab center. Figures 8 and 9 compare the deflection profiles of the control and strengthened specimens at the ultimate loads along the orthogonal and diagonal axes, respectively. The control specimen had the highest deflection values at all locations among the test specimens. Specimen R-MMS had the highest deflection values among the strengthened specimens, but less deflection than the control specimen. Specimen R-R had the lowest deflection profile among the strengthened specimens.

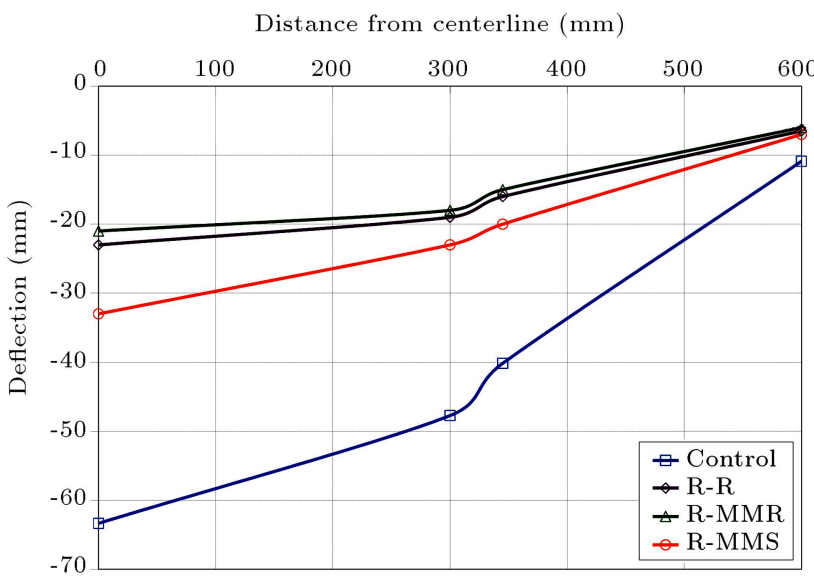

Figure 8. Deflection profile along the orthogonal axis at the ultimate load.

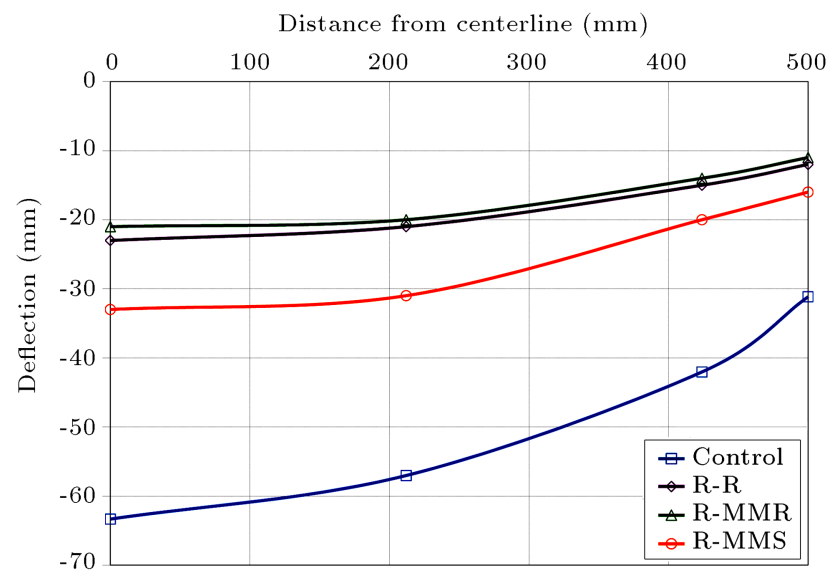

Figure 9. Deflection profile along the diagonal axis at the ultimate load.

\subsection{Cracking patterns and failure modes}

Figure 10 shows the cracking patterns at the tension and compression faces of the specimens after failure. Control specimen failed in pure flexural failure mode by forming the flexural orthogonal yield lines at the slab tension face directly below the loading plates. Yield lines then extended from the corners of the loading plates in the diagonal direction and forked out as they approached the corners of the slab. There was no sudden loss of strength in the load-deflection response of the control specimen, although very large deflection was imposed. The failure of the control specimen was more ductile than those of the strengthened specimens, as indicated in Table 3 . All the strengthened specimens experienced combined flexural and brittle local failure due to punch of the loading plates through the slab in which both flexural yield lines and roughly circular cracks along the perimeter of the loading plates were observed to form simultaneously at failure. For strengthened specimens, significant yielding was observed followed by the initiation of crushing of concrete around the loading plates.

All the strengthened specimens had smaller crack widths than that of the control specimen due to the effect of FRP reinforcements on restraining the crack propagation. It was observed that the load level at which failure occurred and the severity of failure of the specimens was influenced by the presence of the FRP reinforcements. The crack control provided by the FRP reinforcements was optimal when direction of the FRP reinforcements was oriented perpendicular to the crack. The crack outlines for FRP strengthened specimens were similar to each other. For specimens R-MMR and R-MMS, crack distribution at the slab tension face was more concentrated in the $x$ direction, strengthened with GFRP rods.

After failure took place, the loading was continued and measurements were taken to observe the postfailure behavior until the ultimate failure occurred due 

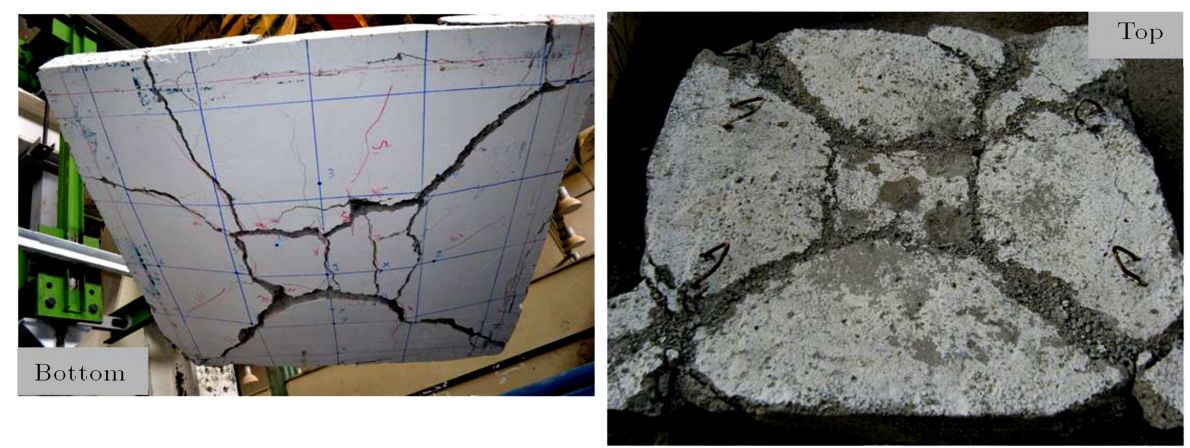

(a) Control specimen

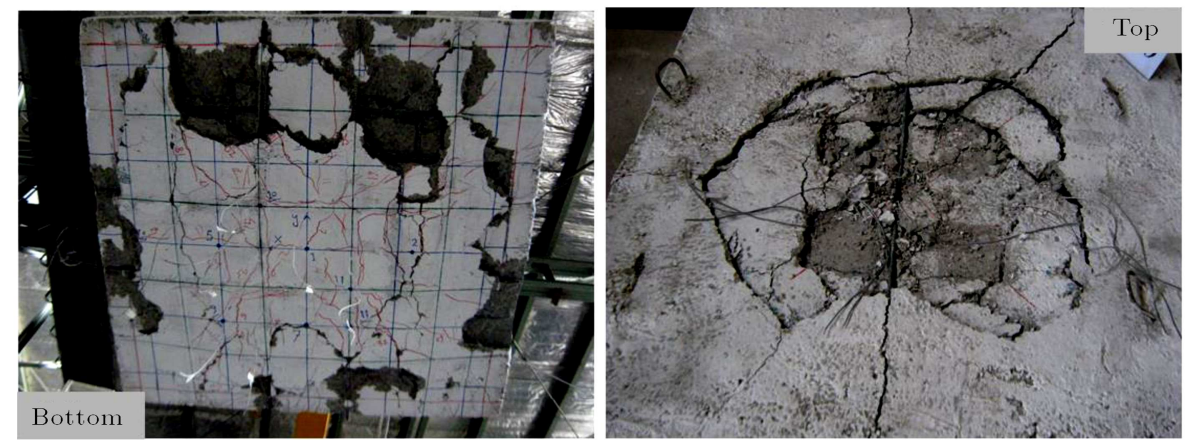

(b) Specimen R-R
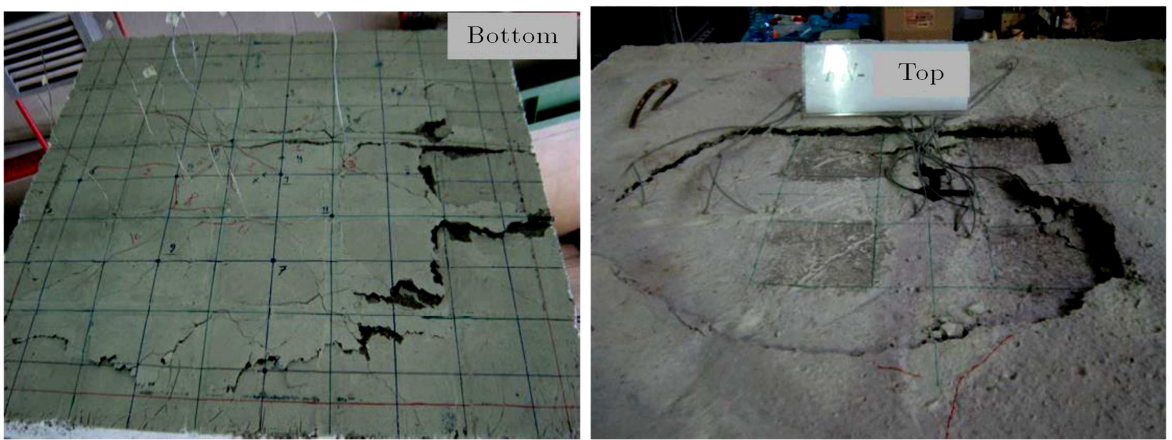

(c) Specimen R-MMR
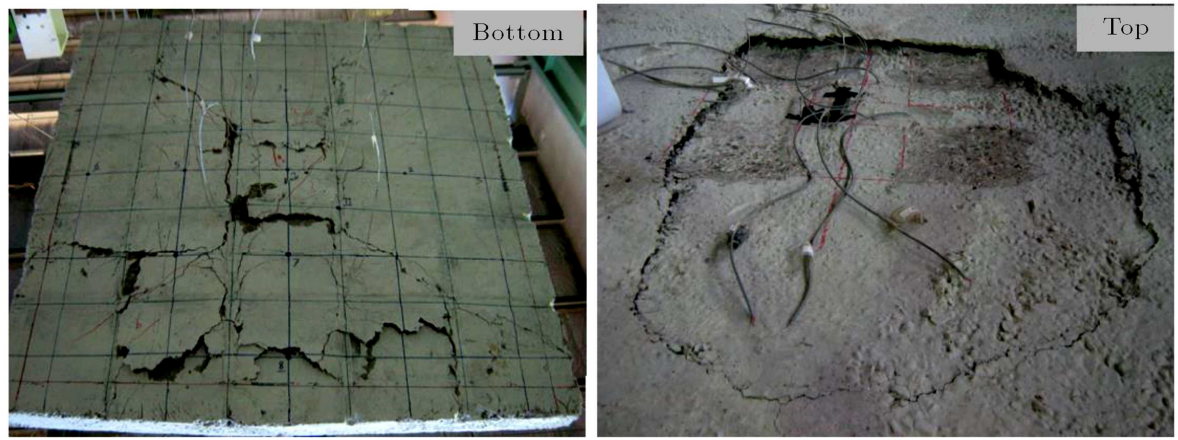

(d) Specimen R-MMS

Figure 10. Cracking patterns of the specimens after failure.

to a combination of anchoring or rupture of the FRP reinforcements and concrete crushing. A drop in load was observed in all strengthened specimens beyond the ultimate load $\left(P_{u}\right)$, as shown in Figure 7 . This drop in load was stabilized at a certain level $\left(P_{p f}\right)$, beyond which the specimens continued carrying approximately the same level of load under increasing deflections. Table 3 provides the comparison of the loads carried after failure. The post-failure load carrying capacities for specimens R-R, R-MMR, and R-MMS were about 29,48 , and $63 \%$ of their ultimate load carrying capacities, respectively, and their post-failure behavior was 


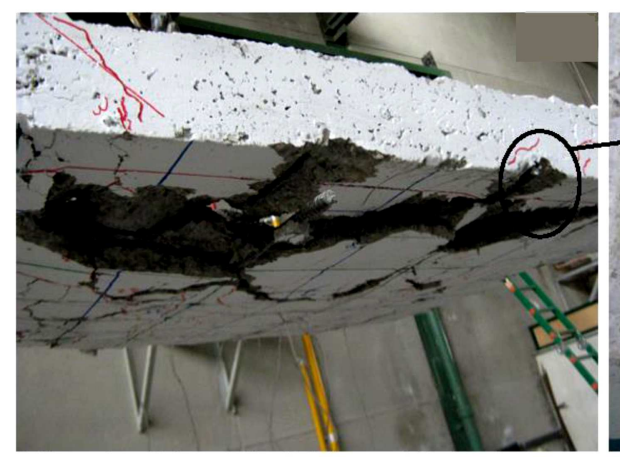

(a)

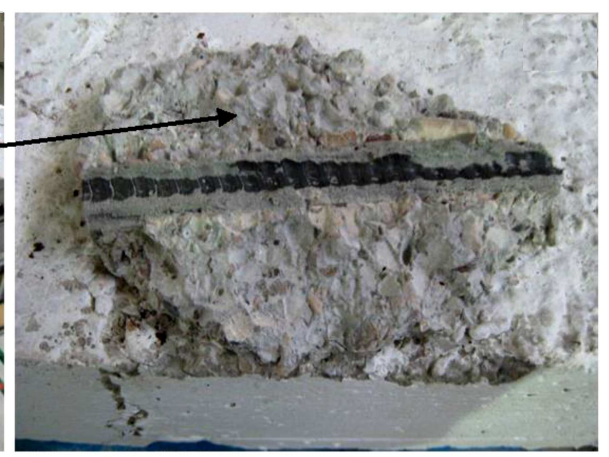

(b)

Figure 11. Failure plane between the slab face and the bonding epoxy of the GFRP NSM rods for specimen R-R.

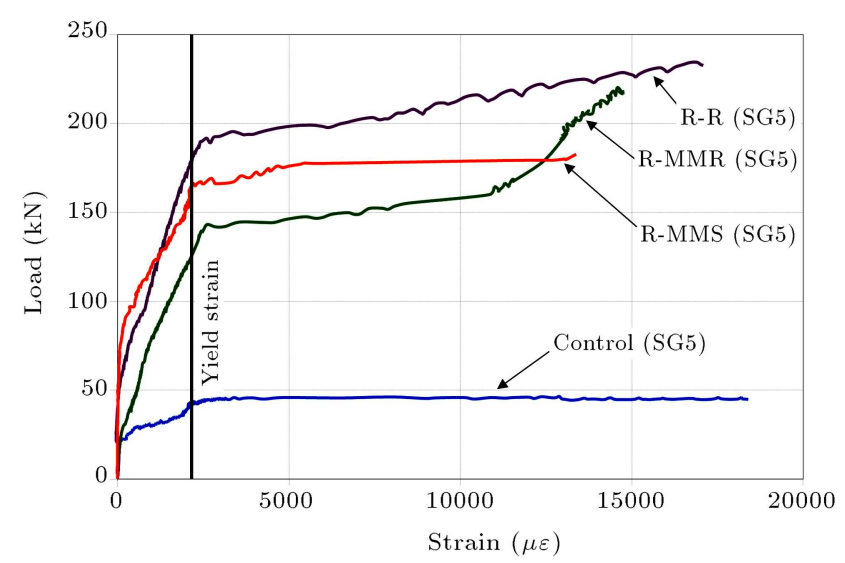

Figure 12. Strain measurements on the steel bars.

stable up to the end of loading. For control specimen, punching of loading plates did not occur and failure was in the form of flexural failure. The post-failure behavior was highly influenced by FRP reinforcements area and configuration, concrete compressive strength, slab reinforcement ratio, and eccentricity of the loading points. At this stage, all strengthened specimens experienced failure of the anchoring of the GFRP rods which was evident from the horizontal shear-off of a thin concrete layer between the slab face and the bonding epoxy of the GFRP rods as a result of large deflection on either side of the crack when failure occurred, as shown in Figure 11(a) and (b) for specimen R-R.

\subsection{Steel and concrete strains}

Strains were measured on the steel bars and on the concrete compressive face of the slabs. Figure 3 shows the locations of the strain gauges. Load versus steel and concrete strain responses for strain gauges that gave maximum strains are shown, respectively, in Figures 12 and 13. The vertical line in Figure 12 illustrates the yield strain for steel bars, determined as 2,160 microstrain from uniaxial tension tests. Yielding of the steel bars was observed in all of the specimens. The maximum steel strain measurement for specimens was well above the yield strain (between 13,000 and 18,000

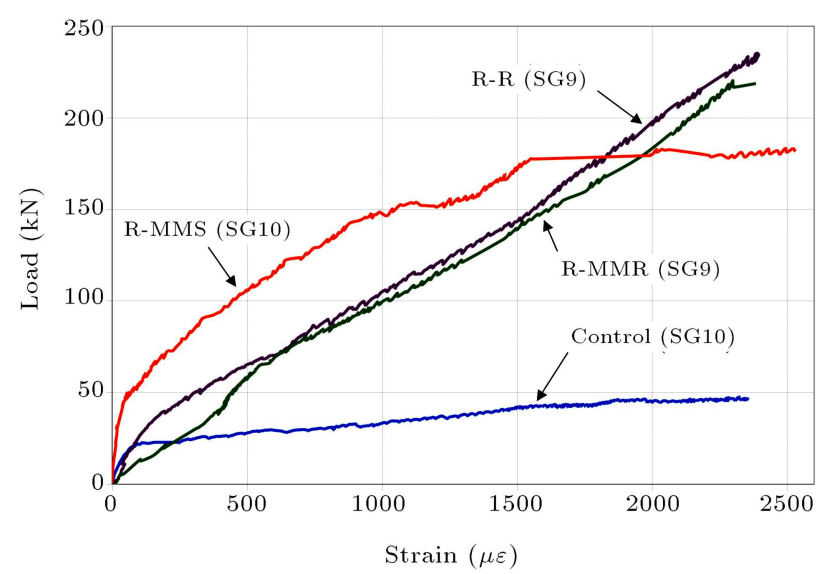

Figure 13. Strain measurements on the concrete compression face of the slabs.

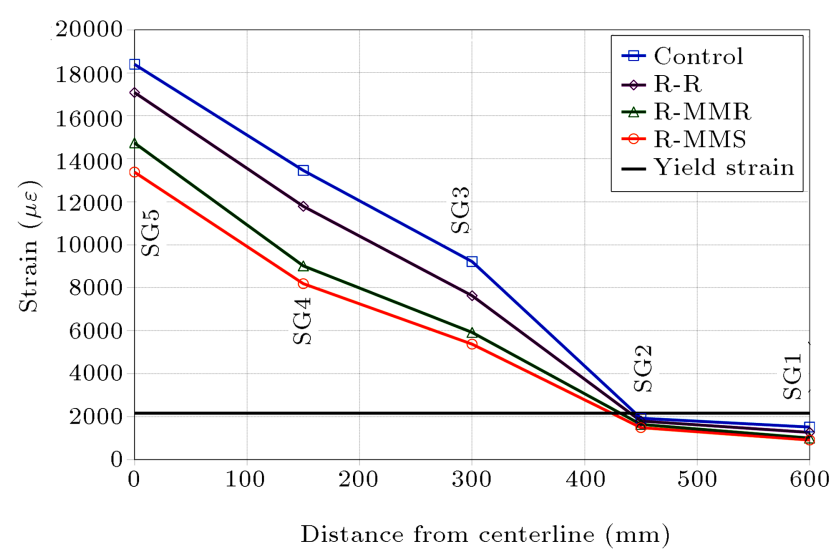

Figure 14. Steel strain profiles at the ultimate load.

microstrain). The maximum concrete compressive strain, reached at the ultimate load of the specimens, was about 2,531 microstrain for specimen R-MMS. This strain level corresponded to about $85 \%$ of the ultimate uniaxial compressive strain of concrete, determined as 2,985 microstrain from compressive cylinder tests.

Figure 14 shows the steel strain profiles at gages 1 to 5 along the orthogonal axis at the ultimate load of the specimens. The horizontal line in this figure 
illustrates the yield strain for steel bars (2,160 microstrain). The steel strain versus distance relationship for all specimens had a nonlinear profile. The highest steel strains at all load levels for all specimens were measured by strain gage 5 located at the slab center. The lower strains were measured by other strain gages located further from the slab center. Initial yielding of steel bars occurred at the slab center and then spread gradually from the center to the edges of the slab. Strengthened specimens had lower steel strain values than that of the control specimen. Applying the FRP reinforcements reduced the internal steel strains and delayed the onset of failure. Strengthened specimens had steel strain values that ranged from 73 to $93 \%$ of those in the control specimen. Although high strain levels in steel bars were reached for strengthened specimens, the pure flexural failure mode was not reached.

\subsection{FRP strains}

Figure 15 shows the load versus the maximum measured FRP reinforcements strain for strengthened specimens. It was observed that FRP strains were small before cracking. After cracking, the FRP reinforcements engaged and started carrying the excessive strains until failure occurred. The maximum strains, developed in the GFRP rods, CFRP MMRs, and CFRP MMSs, were 10,873, 4,419, and 5,540 microstrain, respectively. This corresponded to about 72 , 29 , and $37 \%$ of the ultimate tensile (rupture) strain of the FRP reinforcements, which depended on the slab failure mode and the bond strength between the FRP reinforcements and concrete. In R-MMR and R-MMS specimens, the strain gauges had been bonded on the unsmooth surface of the CFRP fabric of MMRs and MMSs, which resulted in separation of the gauges from the surface of MMRs and MMSs at high strain levels. As a result, the MMRs and MMSs showed lower strain values than that of the GFRP rods.

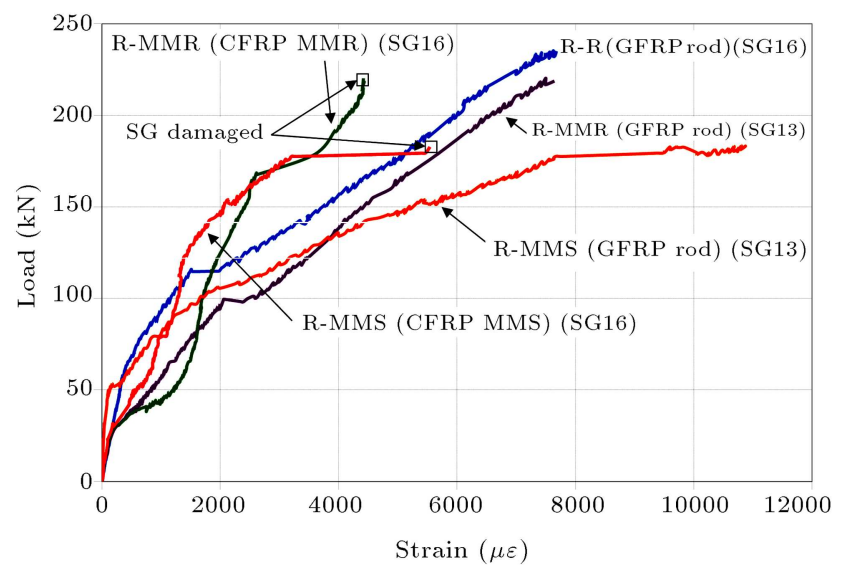

Figure 15. Strain measurements on the FRP reinforcements.

\section{Finite element modeling}

\subsection{Geometry of the developed FE models}

Four FE models were developed to simulate the behavior of the full-scale RC slabs, using the FE code ANSYS [19]. The numerical predictions were compared with the experimental results for load-central deflection response and cracking pattern at failure. The models had the same geometry, dimensions, material properties, loading, and boundary conditions as those of the experimental tested specimens. Also, the developed FE models had the same notation as that of the experimental program. One quarter of the slabs was modeled due to the geometrical, loadings, and boundary conditions symmetry. The steel bars and NSM FRP reinforcements were defined as discrete reinforcement model located near the slab tension face. The nodes on the compressive face of slab, which corresponded to the location of the steel loading plate in the experiment, were coupled in the vertical direction using the constraint equations. Figure 16 shows the general layout of a developed FE model.

\subsection{Description of elements and material properties}

The eight-node structural solid element, SOLID65, was used to model the concrete [19]. Each node of the solid element had three translational degrees of freedom in the $x, y$, and $z$ directions. The element was capable of plastic deformation, cracking in tension (in three orthogonal directions), and crushing in compression. The 3D two-node structural spar element, LINK8, was used to model the steel bars and NSM FRP reinforcements [19]. Each node of the element had three translational degrees of freedom. The element was a uni-axial tension-compression element and was capable of plastic deformation. In order to simplify modeling, the perfect bond between reinforcements (steel and NSM FRP) and solid concrete elements was assumed by sharing the same nodes.

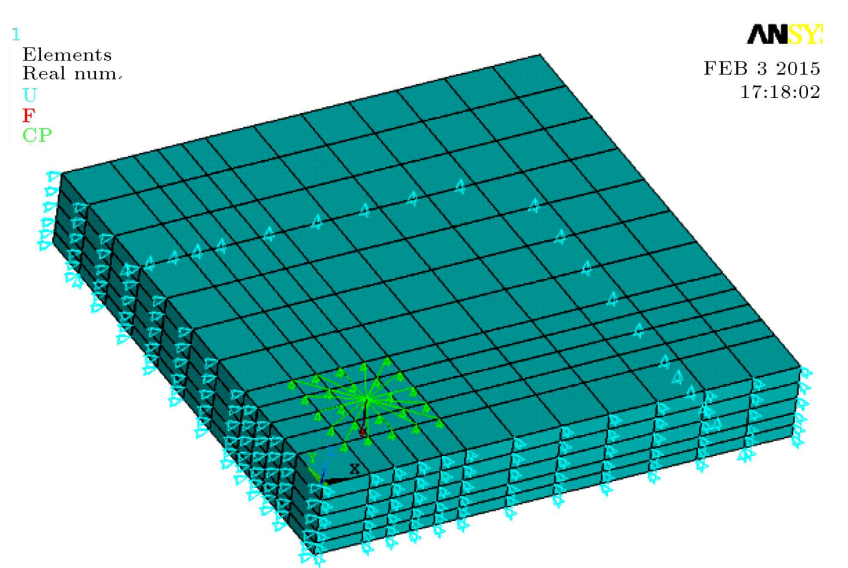

Figure 16. General layout of the developed FE model. 
The William and Warnke [22] failure criterion along with the Drucker-Prager criterion were used to define the constitutive material model for the concrete elements. Drucker-Prager criterion considers the effect of mean normal stress (i.e., confinement) on the yield function and is suitable for modeling the concrete behavior in compression. The behavior of the steel bars was idealized to be bilinear (elasticplastic) with a post-yield strain hardening of $1 \%$ to represent the strain hardening effect of the steel bars as the strain hardening greatly affected the ultimate load carrying capacity of the specimen. The vonMisses failure criterion was used to define yielding of the steel bars. The NSM FRP reinforcements were modeled with elastic-brittle behavior (linear stressstrain curve up to brittle failure) in tension and zero strength and stiffness in compression. The material constitutive models of concrete, steel bars, and NSM FRP reinforcements used in the FE model are shown in Figure 17.

\subsection{Comparison between FE numerical predictions and experimental results}

A comparison was carried out between the FE numerical predictions and experimental results of the loadcentral deflection response and cracking pattern at failure. Figure 18 compares the load-central deflection responses predicted by FE models with the experimental results for all the four slabs. The descending branch of the FE load-central deflection responses was not calculated. As shown in Figure 18, the FE numerical predicted load-central deflection responses agree well with the experimental measurements for all specimens. The load-deflection responses from the FE models were slightly stiffer than those from the experimental results.

Table 4 compares the predicted ultimate loads and deflections of the FE analyses with the tests data. As indicated in Table 4, the maximum deviation between the experimental and predicted numerical results for the ultimate load is less than $7 \%$ for all slabs.

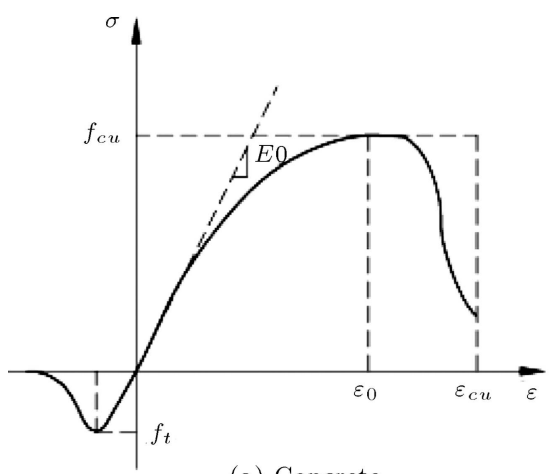

(a) Concrete

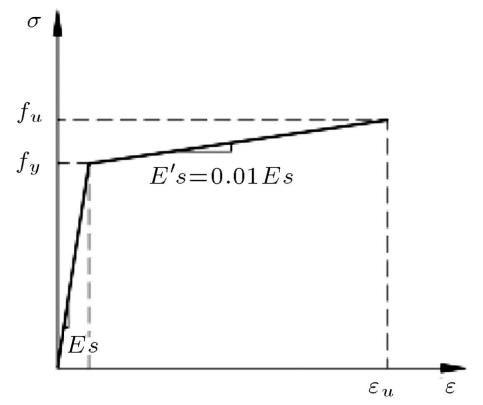

(b) Steel bars

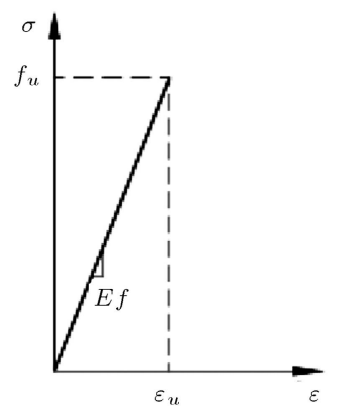

(c) FRP reinforcements

Figure 17. Material constitutive models.
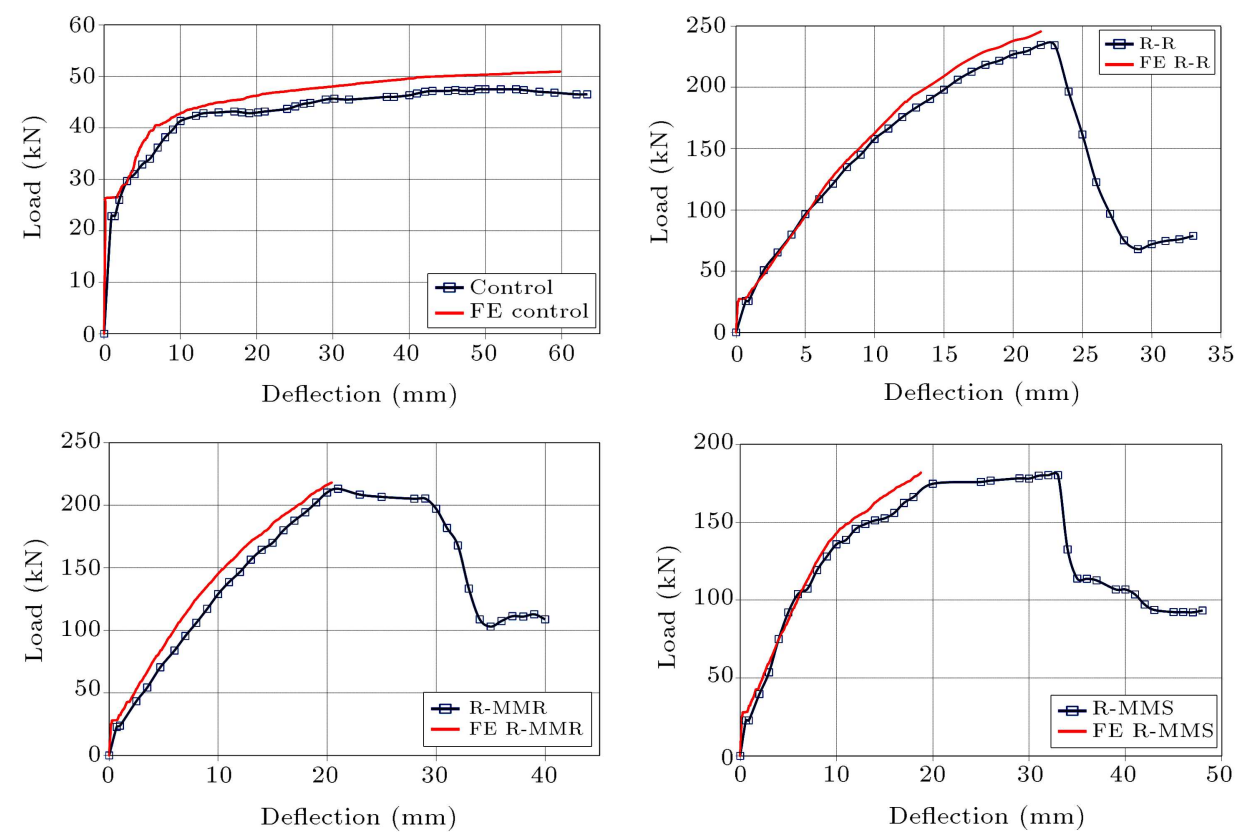

Figure 18. Comparison between FE numerical and experimental results of the load-central deflection response. 
Table 4. Comparison between the predicted FE numerical and experimental results.

\begin{tabular}{|c|c|c|c|c|c|}
\hline \multirow[b]{2}{*}{ Specimen } & \multicolumn{2}{|c|}{ Exp. } & \multicolumn{2}{|c|}{ FE } & \multirow{2}{*}{$\begin{array}{c}\% \text { difference in } \\
P_{u}(\text { FE-Exp. }) / F E\end{array}$} \\
\hline & $\begin{array}{c}P_{u} \\
(\mathrm{kN})\end{array}$ & $\begin{array}{c}\Delta_{u} \\
(\mathbf{m m})\end{array}$ & $\begin{array}{c}P_{u} \\
(k N)\end{array}$ & $\begin{array}{c}\Delta_{u} \\
(\mathrm{~mm})\end{array}$ & \\
\hline Control & 47.50 & 63.35 & 50.92 & 59.79 & 6.7 \\
\hline R-R & 234.50 & 22.93 & 245.53 & 22.06 & 4.5 \\
\hline R-MMR & 213.17 & 21.06 & 218.08 & 20.43 & 2.3 \\
\hline R-MMS & 180.17 & 33.09 & 181.79 & 18.76 & 0.9 \\
\hline
\end{tabular}

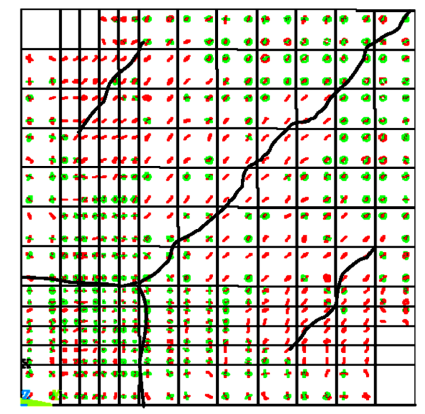

(a) Control

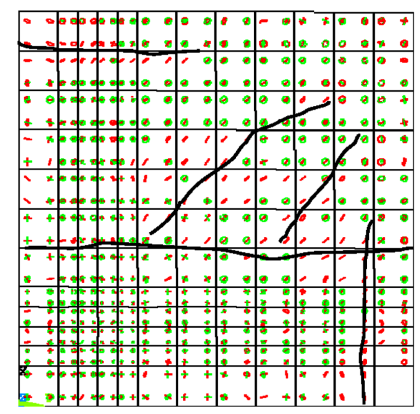

(c) R-MMR

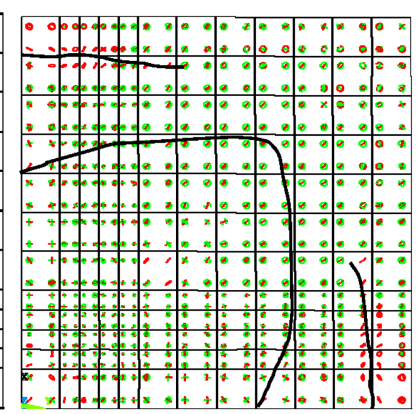

(b) R-R

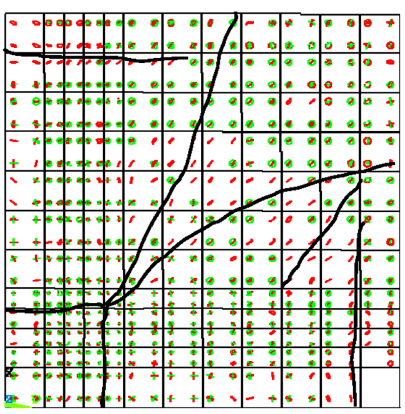

(d) R-MMS
Figure 19. Cracking pattern of FE models at failure load level.

Figure 19(a)-(d) show the cracking pattern obtained from the FE analyses at the last converged load step for all models. The black lines in this figure illustrate the approximate crack pattern for each specimen, which were drawn manually along the length of the cracking signs resulted from ANSYS output. As shown in Figure 19, the cracking patterns from the FE simulations and the actual slabs, reported in Section 4.4., are in reasonably good agreement. It can be concluded that the developed FE models can provide the accurate prediction of the load-central deflection response and cracking pattern at failure for the RC two-way slabs strengthened with NSM FRP reinforcement.

\section{Summary and conclusions}

An effective technique based on the NSM method for flexural strengthening of existing RC two-way slabs with low clear cover thickness is presented in this study. The proposed strengthening technique employs the innovative CFRP MMRs and CFRP MMSs, manufactured manually by CFRP fabric, as flexural reinforcements. An experimental program was carried out and the behavior of slabs strengthened according to this technique was compared to the behavior of the slab strengthened with conventional GFRP rods. A 3D nonlinear simulation was also developed using the FE method and the numerical predictions of loadcentral deflection response and cracking pattern were compared with the experimental results. The following conclusions can be drawn from this study:

- The test results indicated that the use of MMR and MMS reinforcements is a feasible and effectiveness technique for improving the flexural behavior of the RC two-way slabs with low clear cover thickness;

- It can be shown that when the proposed CFRP MMR and CFRP MMS reinforcements are used, the grooves in both $x$ and $y$ directions of the slab can be cut approximately with the same depths. Therefore, strengthening the slabs with low clear cover thickness using NSM method, which was often limited due to the insufficient clear cover thickness in most existing slabs, can be possible;

- Strengthening the RC two-way slabs using NSM FRP reinforcements increases their flexural capacity. The specimens R-R, R-MMR, and R-MMS had increase in the flexural capacities by almost 394, 349, and $279 \%$, respectively, compared with the control specimen. Specimen R-R, strengthened with GFRP rods, showed an increase in ultimate load by 10 and $30 \%$ over those slabs strengthened with CFRP MMRs and CFRP MMSs, respectively;

- All the strengthened specimens failed in combined flexural and local failure modes due to the punch in loading plates through the slab. Failure took place after significant yielding of steel bars. Although high strain levels in steel bars were reached, the pure flexural failure mode was not reached;

- The strengthened specimens had a stiffer behavior than that of the control specimen due to the stiffening effect of FRP reinforcements. Deflection values at the ultimate load of the strengthened specimens 
were between 33 and $52 \%$ of the deflection value of the control specimen;

- The slabs strengthened with CFRP MMRs and CFRP MMSs showed higher ductility compared to the slab strengthened using GFRP rods. It was shown that the increase in flexural capacity was accompanied by a reduction in the ductility of failure;

- The NSM FRP reinforcements reduced the strain in the internal steel bars and resulted in delay in the initiation and controlling propagation of the flexural cracks in slabs;

- There was a reasonably good agreement between the numerical predictions and experimental results in terms of the load-central deflection response and cracking pattern of the specimens.

\section{Acknowledgment}

The authors wish to thank Semnan University Science and Technology Park for financial support and colleagues at the University for technical support. Also, they would like to acknowledge PAYA-SAZ-AZHAND Company for providing epoxy adhesives.

\section{References}

1. ACI Committee 440, Guide for the Design and Construction of Externally Bonded FRP System for Strengthening Concrete Structures, Farmington Hills (MI): American Concrete Institute, ACI 440.2R-08 (2008).

2. Badawi, M. and Soudki, K. "Flexural strengthening of RC beams with prestressed NSM CFRP rods experimental and analytical investigation", Constr. Build. Mater., 23(10), pp. 3292-300 (2009).

3. Hawileh, R.A. "Nonlinear finite element modeling of RC beams strengthened with NSM FRP rods", Constr. Build. Mater., 27(1), pp. 461-71 (2012).

4. Yost, J.R., Gross, S.P., Dinehart, D.W. and Mildenberg, J.J. "Flexural behavior of concrete beams strengthened with near-surface-mounted CFRP strips", ACI Struct. J., 104(4), pp. 430-7 (2007).

5. Bournas, D.A. and Triantafillou, T.C. "Flexural strengthening of reinforced concrete columns with near-surface-mounted FRP or stainless steel", ACI Struct. J., 106(4), pp. 495-505 (2009).

6. De Lorenzis, L. and Teng, J.G. "Near-surface mounted FRP reinforcement: An emerging technique for strengthening structure", J. Compos., Part B Eng., 38(2), pp. 119-43 (2007).

7. El-Hacha, R. and Riskalla, S.H. "Near-surfacemounted fiber-reinforced polymer reinforcements for flexural strengthening of concrete structures", $A C I$ Struct. J., 101(5), pp. 717-26 (2004).
8. Barros, J.A.O., Dias, S.J.E. and Lima, J.L.T. "Efficacy of CFRP-based techniques for the flexural and shear strengthening of concrete beams", J. Cem. Concr. Compos, 29(3), pp. 203-17 (2007).

9. Ceroni, F. "Experimental performances of RC beams strengthened with FRP materials", Constr. Build. Mater., 24(9), pp. 1547-59 (2010).

10. Jalali, M., Sharbatdar, M.K., Chen, J.F. and Jandaghi Alaee, F. "Shear strengthening of RC beams using innovative manually made NSM FRP bars", Constr. Build. Mater., 36, pp. 990-1000 (2012).

11. Barros, J.A.O., Baghi, H., Dias, S.J.E. and Gouveia, A.V. "A FEM-based model to predict the behaviour of $\mathrm{RC}$ beams shear strengthened according to the NSM technique", Eng. Struct J., 56, pp. 1192-1206 (2013).

12. Sharaky, I.A., Torres, L., Comas, J. and Barris, C. "Flexural response of reinforced concrete (RC) beams strengthened with near surface mounted (NSM) fibre reinforced polymer (FRP) bars", Compos. Struct. J., 109, pp. 8-22 (2014).

13. Bonaldo, E., Barros, J.A.O. and Lourenco, P.B. "Efficient strengthening technique to increase the flexural resistance of existing RC slabs", J. Compos. Constr., 12(2), pp. 149-59 (2008).

14. Elgabbas, F., El-Ghandour, A.A., Abdelrahman, A.A. and El-Dieb, A.S. "Different CFRP strengthening techniques for prestressed hollow core concrete slabs: Experimental study and analytical investigation", Compos. Struct. J., 92, pp. 401-11 (2010).

15. Dalfré, G.M. and Barros, J.A.O. "NSM technique to increase the load carrying capacity of continuous RC slabs", Eng. Struct. J., 56, pp. 137-53 (2013).

16. Mostakhdemin Hosseini, M.R., Dias, S.J.E. and Barros, J.A.O. "Effectiveness of prestressed NSM CFRP laminates for the flexural strengthening of RC slabs", Compos. Struct. J., 111, pp. 249-58 (2014).

17. Breveglieri, M., Barros, J.A.O., Dalfré, G.M. and Aprile, A. "A parametric study on the effectiveness of the NSM technique for the flexural strengthening of continuous RC slabs", Compos., Part B Eng., 43(4), pp. $1970-87$ (2012).

18. Foret, G. and Limam, O. "Experimental and numerical analysis of RC two-way slabs strengthened with NSM CFRP rods", Constr. Build. Mater., 22(10), pp. 202530 (2008).

19. ANSYS - Release version 11 "A finite element computer software theory and user manual for nonlinear structural analysis", ANSYS 2007, Inc. Canonsburg, PA (2007).

20. Sharbatdar, M.K. "Concrete columns and beams reinforced with FRP bars and grids under monotonic and reversed cyclic loading", PhD Thesis, University of Ottawa, Canada (2003).

21. ACI committee 318, Building Code Requirements for Structural Concrete, Farmington Hills (MI): American Concrete Institute, ACI 318-99 (1999). 
22. William, K.J. and Warnke, E.P. "Constitutive model for the triaxial behavior of concrete", IABSE Proc., Int. Association for Bridge and Structural Engineering, Zürich, 19, pp.174 (1975).

\section{Biographies}

Pejman Behzard obtained an MS degree in Structural Engineering from Semnan University, Iran, with his thesis on the Punching shear strengthening of reinforced concrete slab-column connections using fiber reinforced polymers, and is currently a $\mathrm{PhD}$ degree candidate at the same institution. He owns a patent related to his thesis and has authored one book and numerous conference papers.

Mohammad Kazem Sharbatdar obtained his MS degree from Amirkabir University, Tehran, Iran, and his $\mathrm{PhD}$ degree from Ottawa University in Canada. He is currently Associate Professor in the Faculty of Civil Engineering at Semnan University, Iran. He has authored 5 books, more than 20 ISI and ISC journal papers and more than 100 conference papers. He has 5 patents. He has also supervised numerous MS and PhD degree theses.

Ali Kheyroddin obtained his MS degree from Iran University of Science and Technology, Iran, and his $\mathrm{PhD}$ degree from McGill University, Canada. He is currently Professor of Civil Engineering at Semnan University, Iran. He is the author of 8 books, more than 35 ISI and ISC journal papers and more than 200 conference papers. He has 4 patents. He has also supervised numerous $\mathrm{PhD}$ and MS degree theses. 